\title{
Familial Hypertrophic Cardiomyopathy
}

\section{Microsatellite Haplotyping and Identification of a Hot Spot for Mutations in the $\beta$-Myosin Heavy Chain Gene}

\author{
Eric Dausse, * Michel Komajda, ${ }^{\star}$ Luc Fetler, ${ }^{\star}$ Olivier Dubourg, ${ }^{\star}$ Cécile Dufour, ${ }^{*}$ Lucie Carrier, ${ }^{\star}$ Claudine Wisnewsky, ${ }^{*}$ \\ Josiane Bercovici, * Christian Hengstenberg, * Sahar Al-Mahdawi, ${ }^{3}$ Richard Isnard, ${ }^{\star}$ Albert Hagege, ${ }^{\star}$ Jean-Brieuc Bouhour," \\ Michel Desnos, ” Jacques Beckmann," Jean Weissenbach, "Ketty Schwartz, * and Pascale Guicheney* \\ ${ }^{*}$ Institut National de la Sante et de la Recherche Médicale, U127, Hôpital Lariboisière, 75010 Paris, France; ${ }^{\ddagger}$ Groupe des \\ Myocardiopathies de la Société Française de Cardiologie, Hôpital Pitié-Salpétrière, 75013 Paris; ${ }^{\S}$ Department of Biochemistry and \\ Molecular Genetics, St. Mary's Hospital Medical School, London W2IPG, England; "Centre d'Etude du Polymorphisme Humain, \\ 75010 Paris, France; and 'Centre National de la Recherche Scientifique, URA 1445, Institut Pasteur, 75015 Paris, France
}

\begin{abstract}
Familial hypertrophic cardiomyopathy (FHC) is a clinically and genetically heterogeneous disease. The first identified disease gene, located on chromosome 14q11-q12, encodes the $\beta$ myosin heavy chain. We have performed linkage analysis of two French FHC pedigrees, 720 and 730, with two microsatellite markers located in the $\beta$-myosin heavy chain gene (MYO I and MYO II) and with four highly informative markers, recently mapped to chromosome 14q11-q12. Significant linkage was found with MYO I and MYO II in pedigree 720, but results were not conclusive for pedigree 730 . Haplotype analysis of the six markers allowed identification of affected individuals and of some unaffected subjects carrying the disease gene. Two novel missense mutations were identified in exon 13 by direct sequencing, $403^{\mathrm{Arg} \rightarrow \mathrm{Lew}}$ and $403^{\mathrm{Arg} \rightarrow \mathrm{Trp}}$ in families 720 and 730 , respectively. The $403^{\mathrm{Arg} \rightarrow \mathrm{Lew}}$ mutation was associated with incomplete penetrance, a high incidence of sudden deaths and severe cardiac events, whereas the consequences of the $403^{\mathrm{Arg} \rightarrow \text { Trp }}$ mutation appeared less severe. Haplotyping of polymorphic markers in close linkage to the $\beta$-myosin heavy chain gene can, thus, provide rapid analysis of non informative pedigrees and rapid detection of carrier status. Our results also indicate that codon 403 of the $\beta$-myosin heavy chain gene is a hot spot for mutations causing FHC. (J. Clin. Invest. 1993. 92:2807-2813.) Key words: familial hypertrophic cardiomyopathy $\bullet$ molecular genetics $\bullet$ mutation hot spot $\bullet \boldsymbol{\beta}$-myosin heavy chain • microsatellite
\end{abstract}

\section{Introduction}

Familial hypertrophic cardiomyopathy $(\mathrm{FHC})^{1}$ is a clinically and genetically heterogeneous cardiac disease transmitted as an autosomal dominant trait with variable penetrance. Symptoms

Address correspondence to Pascale Guicheney, Institut National de la Sante et de la Recherche Médicale, U153, Pavillion Rambuteau, Hôpital Pitié-Salpétrière, 47 boulevard de l'Hôpital, 75013 Paris, France.

Received for publication 27 April 1993 and in revised form 29 June 1993.

1. Abbreviations used in this paper: ECG, electrocardiogram; FHC, familial hypertrophic cardiomyopathy; LOD, logarithim of the odds; LVW, left ventricular end-diastolic wall thickness; MDE, mutation detection enhancement.

J. Clin. Invest.

(C) The American Society for Clinical Investigation, Inc.

$0021-9738 / 93 / 12 / 2807 / 06 \$ 2.00$

Volume 92, December 1993, 2807-2813 are diverse, including syncope, angina, heart failure, and sudden death (even in asymptomatic patients). The major common denominator of these various presentations is ventricular hypertrophy usually associated with microscopic evidence of myocardial fiber disarray $(1,2)$. Linkage of the disease with a locus on chromosome 14q11-q12 was found in approximately one third of the affected families (3-8). The $\beta$-myosin heavy chain gene (MYH7) is the disease gene of this locus, and 16 different missense mutations, localized in exons coding for the head and the head rod regions of the protein, were found in various pedigrees (9-21). The most common mutation is in exon 13, affecting the second nucleotide of codon 403 and results in the substitution of an arginine by a glutamine residue. It was found in eight families of various ethnic origin (9-14), and it is associated with an early onset of the disease and a high frequency of sudden deaths. Other mutations, such as $908^{\text {Leu } \rightarrow \text { Val }}$ in exon 23 , are associated with a less malignant prognosis (10). Very recently, two novel localizations, one on chromosome 1 (22) and one on chromosome 11 (23), without identification of the corresponding disease genes, were reported. Genetic diagnosis of FHC will be difficult because of the considerable genetic heterogeneity that has been identified. Here, we have investigated the use of haplotyping microsatellite markers located within chromosome 14q11-q12 locus to (a) analyze linkage to this locus in pedigrees noninformative with $\beta$-myosin heavy chain gene markers alone and $(b)$ detect carrier individuals. During the course of these studies, we have identified two new missense mutations affecting the first and the second nucleotides of codon 403 .

\section{Methods}

\section{Patient studies}

After informed consent was obtained in accordance with the guidelines set down by the Comité d'Ethique du Centre Hospitalier Universitaire de la Pitié-Salpétrière (Paris), clinical evaluation was performed as previously described, and blood samples were obtained from probands, their blood relatives, and their spouses (24). Subjects underwent detailed clinical and cardiovascular examinations including 12-lead electrocardiogram, M-Mode, two-dimensional echocardiography, and Doppler ultrasonography. The main criteria were the presence of a left ventricular end-diastolic wall thickness ( $\mathrm{LVW}$ ) $>13 \mathrm{~mm}$ under classical echocardiographic incidences in the absence of other known causes (i.e., hypertension, valvular stenosis) (2) and the presence of major abnormalities on electrocardiogram (ECG) such as typical left ventricular hypertrophy or abnormal $Q$ waves, in the absence of any known cause. Subjects were classified as unknown in the following situations: (a) the presence of borderline hypertrophy on echocardiogram (LVW thickness $=13 \mathrm{~mm}$ ) and $/$ or incomplete systolic anterior motion of the mitral leaflet produced by chordae tendinae; $(b)$ normal echocardio- 
gram with minor changes on ECG such as ST-T modifications; $(c)$ death of unknown origin; and $(d)$ deceased subjects without cardiovascular examination as defined above or autopsy data.

Family 720 consisted of 52 individuals, 36 were alive, 33 were studied, 10 of them were affected, and 2 were considered as "unknown": individual III-4, $60 \mathrm{yr}$ old, had an interventricular septum of $13 \mathrm{~mm}$ and normal ECG. Individual IV-1, $20 \mathrm{yr}$ old, had normal echocardiogram but negative $T$ waves in leads D3, VF, negative $P$ waves in D1, VL, QRS axis was $0^{\circ}$. The only child, individual IV-20, $12 \mathrm{yr}$ old, was defined as unaffected, since she had a normal ECG and her LVW thickness value normalized for age, height, and weight was within the normal values $(25)$.

In family 730 , there were 15 individuals, 13 were alive, and 10 were studied. Six were affected, and individual II- 2 was considered an obligate carrier, although the only abnormality consisted of minor changes in the ECG.

Microsatellite typing. Six highly informative dinucleotide (CA) repeats were tested to characterize the genotypes of all subjects: MYO I and MYO II microsatellites, which correspond to intragenic sequences of the MYH7 gene (7), AFM199zf4, AFM079ze5, and AFM242xa9, reported in the genetic map of Weissenbach et al. (26), and AFM084ya 1, a new marker from the Jean Weissenbach microsatellite library. The precise order of the AFM markers with regard to the MYH7 gene has now been established (see Results). All PCR amplifications were performed on $40 \mathrm{ng}$ of genomic DNA using $50 \mathrm{pmol}$ of specific primers and $1 \mathrm{U}$ of Taq DNA polymerase (Boehringer Mannheim, Indianapolis, IN). The time and temperature cycle conditions were: $35-40$ cycles of $40 \mathrm{~s}$ at $94^{\circ} \mathrm{C}, 30 \mathrm{~s}$ at $55^{\circ} \mathrm{C}$ without extension, and one additional cycle of $3 \mathrm{~min}$ at $72^{\circ} \mathrm{C}$ in a DNA thermal cycler ( $\mathrm{PHC}$; Techne, Cambridge, United Kingdom). PCR products were resolved according to size by denaturing gel electrophoresis and transferred to Hybond $\mathrm{N}^{+}$membranes (Amersham Corp, Arlington Heights, IL). (CA $)_{15}$ oligonucleotides were tailed with dNTP using terminal transferase (Boehringer Mannheim). Membranes were hybridized overnight at $42^{\circ} \mathrm{C}$ with the tailed $(\mathrm{CA})_{\mathrm{n}}$ probe labeled with horseradish peroxydase and specific binding was revealed using the enhanced chemiluminescence detection system (kit RPN 2101; Amersham Corp.).

Detection of DNA heteroduplexes. Mutations in Families 720 and 730 were detected by analyzing amplified MYH7 exons with mutation detection enhancement (MDE) gels (Hydrolink-MDE gel; AT Biochem, Malvern, PA (27). Oligonucleotide primers of exons 5, 9, 14, 16, $17,19,20$, and 23 were chosen in intronic flanking regions (28) with the OLIGO program and those of exon 13 were taken from Epstein et al. (10). Amplifications for MDE analysis were performed using the same conditions as for the (CA) repeat amplification except that all PCR reactions were performed using $160 \mathrm{ng}$ of genomic DNA and the extension at $72^{\circ} \mathrm{C}$ was for $2 \mathrm{~min}$. Before electrophoresis, PCR products were denatured for $4 \mathrm{~min}$ at $94^{\circ} \mathrm{C}$, then cooled slowly for $1 \mathrm{~h}$ until they reached room temperature; this allowed a random reannealing of the mutated strand with the normal strand (heteroduplexes) and of the normal strand with the normal strand or the mutated strand with the mutated strand (homoduplexes). 20\% of the PCR products were loaded on nondenaturing Hydrolink-MDE gels and electrophoresed in $0.6 \mathrm{X}$ Tris-borate/EDTA buffer at $300 \mathrm{~V}, 4 \mathrm{~mA}, 6 \mathrm{~W}$ for $18 \mathrm{~h}$ at room temperature. Normal and altered migration resulting from conformation polymorphism was visualized by staining with $1 \mu \mathrm{g} / \mathrm{ml}$ ethidium bromide.

Sequencing. Single-strand templates of exon 13 PCR fragments were produced by an asymmetric PCR analysis in each sense (29) and were sequenced using the dideoxynucleotide chain termination method (Sequenase kit; United States Biochemical Corp., Cleveland, $\mathrm{OH})$. The asymmetric PCR and the sequencing reactions were performed using internal oligonucleotide primers.

Analysis of restriction enzyme site polymorphisms. After extraction by phenol/chloroform and precipitation by ethanol, exon 13 PCR products were digested for $2 \mathrm{~h}$ at $37^{\circ} \mathrm{C}$ by $10 \mathrm{U}$ of the following restriction enzymes: Aval (Boehringer Mannheim) for families 730 and 720 , Styl (Boehringer Mannheim) for family 730 and PflMI (United States
Biochemical Corp.) for family 720 . The digested fragments were separated by electrophoresis on $4 \%$ Nusieve agarose gels (FMC Corp. BioProducts, Rockland, ME) and were visualized either by ethidium bromide staining of the gel or after transfer onto Hybond $\mathrm{N}^{+}$membrane by hybridization with random primed radiolabeled PCR amplified exon 13.

Statistical analysis. Two- and three-point logarithm of the odds (LOD) scores were calculated with the MLINK and LINKMAP programs, respectively, of the LINK AGE package version 5.1 (30) assuming an autosomal dominant FHC gene with a frequency of 0.0001 , an equal female and male recombination rate, and equal marker allele frequencies. Because of the clinical variability of FHC and its age-dependent expression, LOD scores were calculated with four liability classes and penetrance increasing from 0.46 between 0 and $20 \mathrm{yr}$ of age, 0.61 between 20 and $40 \mathrm{yr}, 0.9$ between 40 and $70 \mathrm{yr}$, to 1 for subjects who were $\geq 70 \mathrm{yr}$ (23). Phenocopy rates were as follows: 0.001 between 0 and $20 \mathrm{yr}$ of age, 0.002 between 20 and $40 \mathrm{yr}, 0.003$ between 40 and $70 \mathrm{yr}$, and 0.004 above $70 \mathrm{yr}$. With the assumption of maximal heterozygosity and age-dependent penetrance, simulated two-point LOD scores were 5.31 for family 720 and 1.28 for family 730 at $\theta=0.0$.

\section{Results}

Two- and multi-point LOD scores. Six highly informative markers (MYO I and MYO II corresponding to intragenic sequences of the MYH7 gene and four AFM markers that have been mapped nearby) were used to generate two-point LOD scores for the two families (Tables I and II). Family 720 gave significant maximum LOD scores at $\theta=0.0$ with MYO I and MYO II of 3.39 and 3.34, respectively. AFM079ze5 was poorly informative in this family, and no recombinant was detected. The other markers, AFM199zf4, AFM084yal and AFM242xa9 gave nonsignificant positive LOD scores whatever the recombination fractions. Family 730 showed slightly positive maximum LOD scores between 1.22 and 1.28 at $\theta=0.0$ for MYO I, MYO II, AFM079ze5, and AFM084yal. Three-point analysis (MYO I, MYO II, and the disease) gave maximal LOD scores of 3.73 for family 720 and of 1.52 for family 730 for a recombination fraction of 0.0 . All these results indicate that the gene responsible for the disease is linked to the $\beta$-myosin heavy chain gene locus in family 720 , but a similar linkage to the MYH7 locus could not be established for family 730 .

Haplotyping of microsatellite markers. To determine the order of the new AFM markers with respect to MYH7, we used the available linkage data obtained with pSC14, an intragenic biallelic probe of MYH7 (4), and the new AFM markers which have been genotyped in several CEPH (Centre d'Etude du Poly-

Table I. Two-point LOD Scores of FHC and Six Microsatellite Markers Mapped on 14q11-q12 in Family 720

\begin{tabular}{lcccccc}
\hline & & \multicolumn{5}{c}{ Recombination fractions $(\theta)$} \\
\cline { 3 - 7 } \multicolumn{1}{c}{$\begin{array}{c}\text { Marker } \\
\text { name }\end{array}$} & Locus & 0.00 & 0.01 & 0.05 & 0.10 & 0.20 \\
\hline AFM199zf4 & D14S72 & 0.70 & 1.19 & 1.55 & 1.53 & 1.20 \\
MYO I & MYH7 & 3.39 & 3.34 & 3.12 & 2.82 & 2.15 \\
MYO II & MYH7 & 3.34 & 3.29 & 3.09 & 2.81 & 2.18 \\
AFM079ze5 & D14S64 & 0.56 & 0.56 & 0.55 & 0.52 & 0.43 \\
AFM084ya1 & $*$ & -0.002 & 0.56 & 1.09 & 1.23 & 1.11 \\
AFM242xa9 & D14S80 & 0.08 & 0.65 & 1.11 & 1.19 & 1.00 \\
& & & & & &
\end{tabular}

* The locus number of this marker is requested to genome data base. 
Table II. Two-point LOD Scores of FHC and Five Microsatellite Markers Mapped on 14q11-q12 in Family 730

\begin{tabular}{lrrrrr}
\hline \multirow{2}{*}{$\begin{array}{c}\text { Marker } \\
\text { name }\end{array}$} & \multicolumn{5}{c}{ Recombination fractions $(\theta)$} \\
\cline { 2 - 6 } & \multicolumn{1}{c}{0.00} & \multicolumn{1}{c}{0.01} & 0.05 & 0.10 & 0.20 \\
\hline AFM199zf4 & -0.81 & -0.35 & 0.13 & 0.29 & 0.35 \\
MYO I & 1.28 & 1.25 & 1.15 & 1.02 & 0.75 \\
MYO II & 1.22 & 1.19 & 1.10 & 0.97 & 0.72 \\
AFM079ze5 & 1.28 & 1.25 & 1.15 & 1.02 & 0.75 \\
AFM084ya1 & 1.28 & 1.25 & 1.15 & 1.02 & 0.75 \\
& & & & & \\
\hline
\end{tabular}

morphisme Humain) families. By multipoint analysis of the marker alleles in these families, the most likely order (and corresponding recombination fractions) was the following: AFM199zf4, pSC14, AFM079ze5 and AFM242xa9 (0.10, $0.03,0.04)$. AFM084yal was found to be tightly linked to AFM079ze5 (0.001). By haplotyping the alleles of these various markers in family 720 ( see Fig. 1), we were able to map AFM084ya 1 distal to AFM079ze5, as otherwise double recombinations would have occurred for individuals IV-6 and IV-7 between the markers AFM079ze5, AFM084yal and AFM242xa9 (AFM242xa9 alleles not shown). We conclude that the order of these markers is the following: AFM199zf4, MYO I, MYO II, AFM079ze5, AFM084ya1, and AFM242xa9.

In Figs. 1 and 2 the haplotypes of the markers AFM199zf4, Myo I, Myo II, AFM079ze5, and AFM084yal are shown. In family 720 , most of the affected subjects received the complete haplotype 5-3-6-3-2 for AFM199zf4, MYO I, MYO II, AFM079ze5, and AFM084ya1 (Fig. 1). Five fourth-generation individuals who were diagnosed as being unaffected carried this full haplotype and in all cases, it is clear that they received this haplotype from their affected parent. These subjects are individuals IV-8 ( 26 yr old ), IV-9 (24 yr old), IV-17 ( $23 \mathrm{yr}$ old ), IV-20 (12 yr old), and IV-21 (28 yr old). Using only MYO I and MYO II as markers we would not have been able to detect whether individual IV-14 was carrying or not the disease gene, since his two parents had the same haplotype 3-6 for MYO I and MYO II. In family 730, seven out of the nine blood-related individuals carried the haplotype 3-2-1-2 for MYO I, MYO II, AFM079ze5, and AFM084ya1. This haplo-

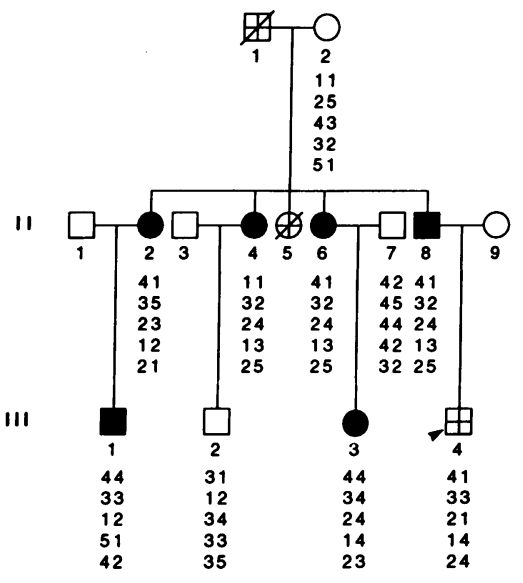

Figure 2. Inheritance of FHC and chromosome $14 \mathrm{q} 11$ marker haplotypes in family 730 . See legend of Fig. 1. type, which was transmitted by the deceased grandfather, cosegregated with the disease and was also carried by the unknown individual III-4. Although the LOD scores were nonsignificant, it seems that MYH7 was most probably the disease gene in this family.

Identification of the $403^{\mathrm{Arg} \rightarrow \mathrm{Leu}}$ mutation in family 720 . Exons 5, 9, 13, 14, 16, 17, 19, 20, and 23 of the MYH7 gene, amplified by PCR from the DNA of family members, were examined on Hydrolink-MDE gels. DNA heteroduplexes migrating more slowly than the homoduplexes were only detected for exon 13-containing fragments amplified from DNA from affected individuals. This polymorphism was detectable in affected subjects and in the healthy young adults carrying the affected haplotype. Direct sequencing of this fragment showed the presence of a $\mathrm{G}$ and a $\mathrm{T}$ at the same position corresponding to the second nucleotide of the codon 403 (Fig. 3), and the presence of a $\mathrm{C}$ and $\mathrm{A}$ at the same position when the other strand was sequenced (data not shown). This $G \rightarrow T$ transversion results in the replacement of an arginine 403 (CGG) by a leucine (CTG). This mutation destroys a Aval site, thus lengthening the 137 and $130 \mathrm{bp}$ fragments found in normal individuals to a 267-bp fragment (Fig. 4). In addition, this mutation creates a new PflMI restriction enzyme site, thus, shortening the 183-bp fragment found in normal individuals to two fragments of 132 and $51 \mathrm{bp}$ that were found in all affected members of this family, in the unknown individual IV-1 and in

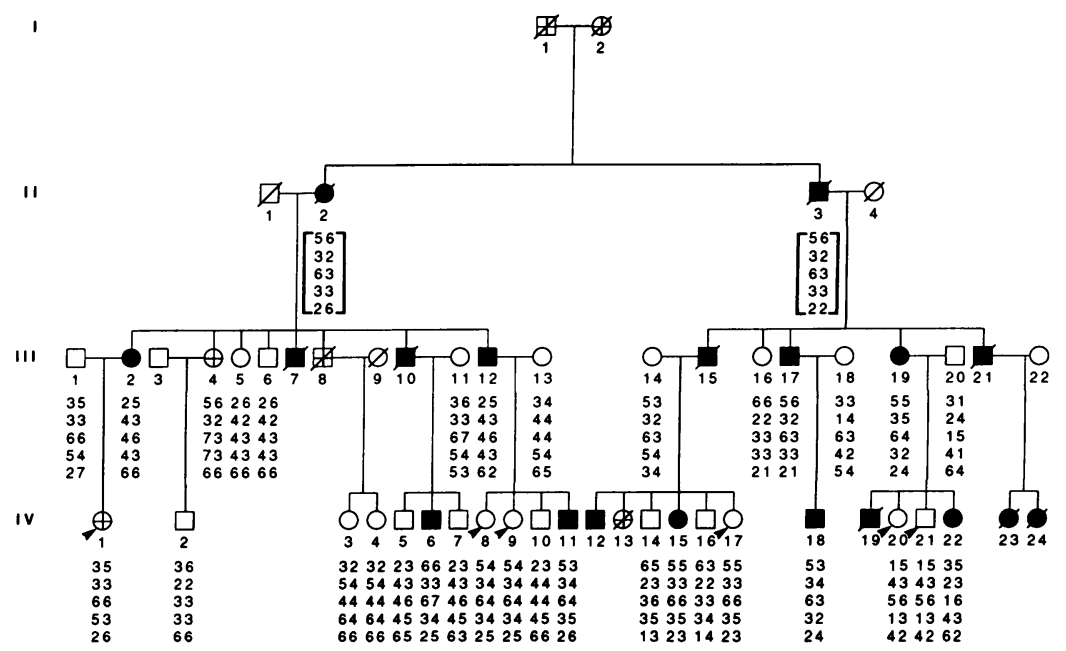

Figure 1. Inheritance of FHC and chromosome 14q11 marker haplotypes in family 720 . The pedigrees are presented using standard nomenclature. Males (squares) and females (circles) are identified by generation and subject number. The disease status of each individual is indicated by shading (as follows): closed symbols, affected; open symbols, unaffected; symbols with a cross, unknown. Deceased individuals are represented by a slash. The arrows indicate genotypic carriers. Alleles are listed from top to bottom: AFM199zf4, MYO I, MYO II; AFM079ze5, AFM084yal. 


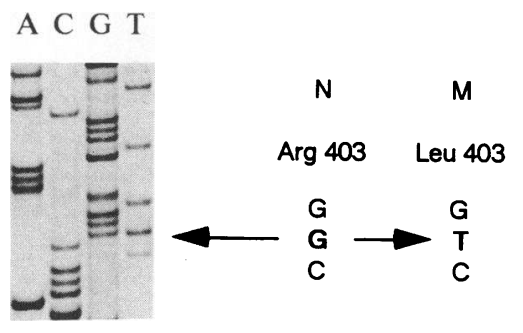

$\mathrm{T}$ at the same position corresponding to the second nucleotide of the codon 403 (indicated by an arrow). N, normal; M, mutant.

the five unaffected individuals of the fourth generation carrying the affected haplotype (IV-8, IV-9, IV-17, IV-20, and IV-21).

Identification of the $403^{\text {Arg } \rightarrow \text { Trp }}$ mutation in family 730 . The search for heteroduplexes among the MYH7 gene exons in members of family 730 by the MDE technique revealed the presence of a polymorphism in exon 13. Direct sequencing in both directions of the exon 13 fragments showed the presence of a $\mathrm{C}$ and $\mathrm{a} \mathrm{T}$ at the same position corresponding to the first nucleotide of the codon 403 (Fig. 5) or by the presence of a $\mathrm{G}$ and $\mathrm{a} A$ at the same position when the other strand is sequenced (data not shown). This $\mathrm{C} \rightarrow \mathrm{T}$ transition results in the replacement of arginine 403 (CGG) by a tryptophan (TGG). This mutation also destroys the Aval site (data not shown) and creates a new StyI restriction enzyme site (Fig. 6), thus shortening the 167-bp fragment found in normal individuals to a 136and a 31-bp fragment that are found in all affected members of this family, as well as in the unknown individual III-4 who carried the affected haplotype, but not in the two unaffected blood related subjects I-2, III-2.

Clinical characteristics of the $403^{\mathrm{Arg} \rightarrow \mathrm{Le} u}$ mutation. In family 720 , FHC was diagnosed in nine affected living (and nontransplanted ) subjects. Left ventricular hypertrophy was asymmetrical (septum vs posterior wall thickness ratio: mean \pm SD
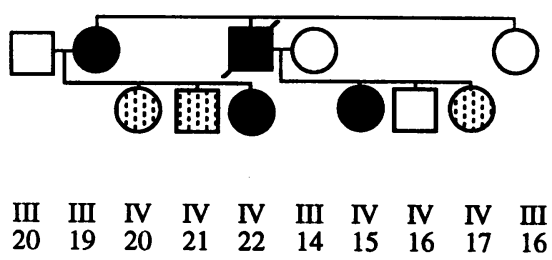

Ava I

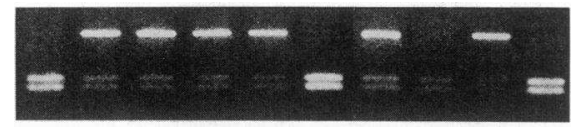

267

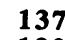

130

\section{PfIM I}

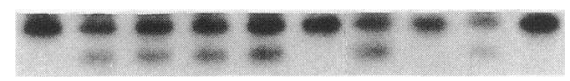

183

132

Figure 4. Genotypic diagnosis by restriction enzyme digestions in family 720 . Individuals of family 720 shown on this figure are identified by their genealogical numbers. The abolition of the Aval restriction enzyme site induces the presence of a new uncut fragment of 267 bp in the affected individuals (black symbols) and in the unaffected carriers (spotty symbols). The creation of a PflMI site induces the presence of a new 132-bp fragment in all affected subjects and carriers. All the members of the families have been studied and the digestion products cosegregated with the disease.

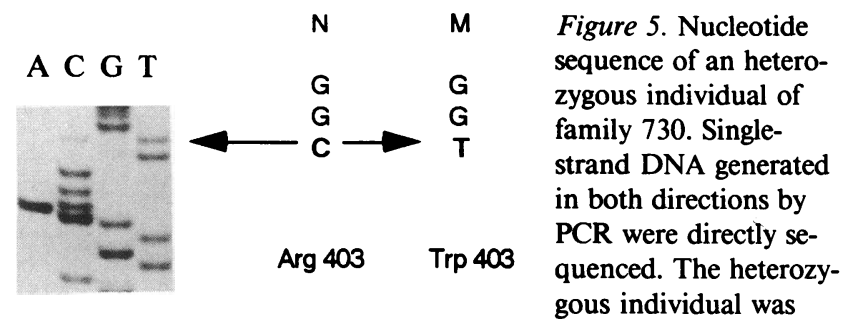

characterized by the presence of a $\mathrm{C}$ and a $\mathrm{T}$ at the same position corresponding to the first nucleotide of the codon 403 (indicated by an arrow). $\mathrm{N}$, normal; $\mathrm{M}$, mutant.

$=2.1 \pm 0.4)$ and pronounced (interventricular septum thickness: mean $\pm \mathrm{SD}=20.7 \pm 5.2 \mathrm{~mm}$; range $=14-30 \mathrm{~mm}$ ).

There was a high incidence of deaths and cardiac events in this family (see Table III): three sudden deaths at the ages of 15,16 , and 24 yr (individuals IV-19, IV-23, IV-24, respectively), two heart transplantations at the ages of 49 and $59 \mathrm{yr}$ (individuals III-12 and III-7, respectively) and one cardiac failure at the age of $58 \mathrm{yr}$ (individual III-10). The hearts of these last three individuals exhibited dilation of the cardiac cavities associated with a marked hypertrophy of left ventricular and muscle fibers ( diameter $=35-50 \mu \mathrm{m}$ ). In contrast, the autopsy of individual IV-24 exhibited a typical form of asymmetrical $\mathrm{HCM}$ without any sign of dilation.

Among the 20 living individuals of the fourth generation, 12 carried the mutation: as shown in Table IV, six individuals had echocardiographic evidence of left ventricular hypertrophy $(17-30 \mathrm{yr}$ old, interventricular septum thickness $=16-27 \mathrm{~mm})$ with or without abnormal 12-lead ECGs and six other individuals showed no sign of interventricular ventricular hypertrophy $(12-28$ yr old, septum thickness $=8-11 \mathrm{~mm})$. The $403^{\mathrm{Arg} \rightarrow \mathrm{Leu}}$ mutation was thus associated in this family with only a partial penetrance in adults.

Clinical characteristics of the $403^{\text {Arg } \rightarrow \text { Trp }}$ mutation. The degree of LV hypertrophy in individuals of Family 730 carrying the mutation is given in Table V. Interventricular septum thickness did not exceed $17 \mathrm{~mm}$. The affected individuals II-2, III-1, and III-3 (51, 30, and 33 yr old, respectively) showed no sign of left ventricular hypertrophy on echocardiogram and affected status diagnosis was based on the presence of important electrocardiographic abnormalities. Moreover, there was no evidence of sudden death or heart failure in this small fam-

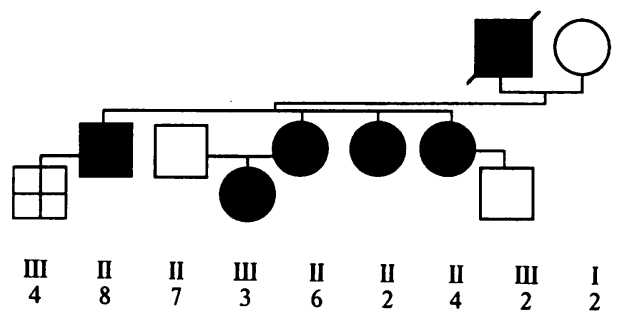

Sty I

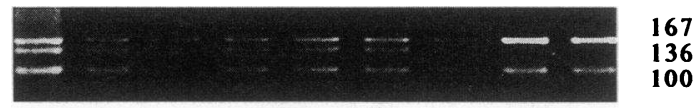

Figure 6. Genotypic diagnosis by restriction enzyme digestion in family 730 . Individuals are identified by their genealogical numbers. The creation of a Styl site induces the apparition of a new 136-bp fragment in the affected and unknown individuals. 
Table III. Ages and Causes of Death in Family 720

\begin{tabular}{|c|c|c|}
\hline $\begin{array}{l}\text { Subject } \\
\text { number }\end{array}$ & $\begin{array}{l}\text { Clinical } \\
\text { status }\end{array}$ & Cause of death \\
\hline II-2 & Affected & Obligate carrier, deceased at 74 yrs \\
\hline II-3 & Affected & Obligate carrier, deceased at 90 yrs \\
\hline III-7 & Affected & $\begin{array}{l}\text { Transplanted at } 59 \mathrm{yr} \text {, deceased at } 60 \mathrm{yr} \text {, } \\
\text { dilated form of cardiomyopathy }\end{array}$ \\
\hline III-8 & Unknown & Sudden death at $65 \mathrm{yr}$ \\
\hline III-10 & Affected & $\begin{array}{l}\text { Deceased at } 58 \mathrm{yr} \text {, dilated form of } \\
\text { cardiomyopathy }\end{array}$ \\
\hline III- 15 & Affected & Traumatic cause \\
\hline III-21 & Affected & Deceased at 66 yr after noncardiac surgery \\
\hline IV-13 & Unknown & Traumatic cause at $16 \mathrm{yr}$ \\
\hline IV-19 & Affected & Sudden death at $15 \mathrm{yr}$ \\
\hline IV-23 & Affected & Sudden death at $16 \mathrm{yr}$ \\
\hline IV-24 & Affected & Sudden death at $24 \mathrm{yr}$, autopsy proven \\
\hline
\end{tabular}

ily. This finding suggests that the $403 \mathrm{Arg} \rightarrow$ Trp mutation may not be as malignant as the $403 \mathrm{Arg} \rightarrow$ Leu mutation.

\section{Discussion}

The results of this study show that in two families with FHC, haplotyping for microsatellites closely linked to the $\beta$-myosin heavy chain gene on chromosome 14q11-q12 allows identification of the defective allele, even in small pedigrees. Since a minimum of at least three different genes can cause FHC, it will be of great interest to screen families to determine which disease gene they carry. The panel of microsatellite markers described here should provide a useful tool to perform this analysis on chromosome 14, and equivalent panels will soon be available for the other chromosomal localizations recently described $(22,23)$. This can now be used to characterize the genetic origin of the disease in new families and to identify unaffected carriers.
The novel mutation in exon $13,403^{\mathrm{Arg} \rightarrow \mathrm{Trp}}$, is a $\mathrm{C}$ to $\mathrm{T}$ transition at the first nucleotide of codon 403. The mutation previously reported in exon $13,403^{\mathrm{Arg} \rightarrow \mathrm{Gln}}$, is a $\mathrm{G}$ to $\mathrm{A}$ transition at the second nucleotide of the same codon. These two mutations are consistent with the accidental deamination of 5-methylcytosine in a $\mathrm{CpG}$ doublet. It has now been established that the $\mathrm{CpG}$ dinucleotides play a prominent role in the emergence of mutations in man (31). In higher vertebrates, the majority of the cytosines belonging to $5^{\prime} \mathrm{CpG} 3^{\prime}$ doublets are 5-methylated and the accidental deamination of a 5-methylcytosine leads to a transition to thymine, which is not excised by the DNA repair system, thus resulting in an irreversible point mutation. Such transitions may occur on either the coding or the noncoding strand of the gene, thus resulting in the replacement of a CG by either TG or CA. The association of these two point mutations at the same codon level, resulting in the replacement of an arginine by a tryptophan or a glutamine, has already been described in several genetic diseases such as phenylketonuria and hemophilia $A$ and $B(32,33)$. By analyzing the numerous mutations reported in the human Factor IX gene, it has been shown that $\mathrm{C} \rightarrow \mathrm{T}$ and $\mathrm{G} \rightarrow \mathrm{A}$ transitions at the dinucleotide $\mathrm{CpG}$ are increased by $\geq 26$-fold relative to other transitions at any other dinucleotide, and that they are clearly the most frequent missense mutations responsible for human diseases (33). The second mutation observed here, $403^{\mathrm{Arg} \rightarrow \mathrm{Leu}}$, is a transversion occurring at the second nucleotide of codon 403 residue. In human Factor IX mutations, transversions at $\mathrm{CpG}$ dinucleotides are elevated by approximately sevenfold relative to other transversions reinforcing the fact that methylated $\mathrm{CpG}$ dinucleotides are mutation hot spots (33). The $\mathrm{CpG}$ dinucleotide of codon 403 of the $\beta$-myosin heavy chain gene, therefore, has all the characteristics of a mutation hot spot: $(a)$ independent occurrence of the two typical types of transitions and of one transversion at the same locus and $(b)$ high frequency of these mutations, since they concern 10 out of $\sim 30$ families with known mutations (9-21). The missense mutation $403^{\mathrm{Arg} \rightarrow \mathrm{Gin}}$ probably arose more than once during human evolution since it has been found in several Caucasian families

Table IV. Comparison of the Ages, Clinical Status, and Echocardiographic and Electrocardiographic Data of Family 720 Fourth Generation Individuals Carrying the Mutation

\begin{tabular}{|c|c|c|c|c|c|c|}
\hline $\begin{array}{l}\text { Subject } \\
\text { number }\end{array}$ & Sex/age & $\begin{array}{l}\text { Clinical } \\
\text { status }\end{array}$ & $\mathbf{s}$ & LVFW & SAM & ECG \\
\hline & $y r$ & & $m m$ & $\mathrm{~mm}$ & & \\
\hline IV-6 & $\mathrm{M} / 23$ & Affected & 18 & 12 & + & ST-T, $Q\left(D_{2}, D_{3}, V_{F}\right)$ \\
\hline IV-11 & $\mathbf{M} / 17$ & Affected & 16 & 10 & + & LVH \\
\hline IV-12 & $\mathrm{M} / 20$ & Affected & 22 & 9 & + & Missing data \\
\hline IV-15 & $\mathrm{F} / 21$ & Affected & 27 & 11 & + & $\mathrm{LAD} ; \mathrm{Q}\left(\mathrm{D}_{3}\right) \mathrm{ST}-\mathrm{T}\left(\mathrm{D}_{3}, \mathrm{~V}_{\mathrm{F}}\right)$ \\
\hline IV-18 & $\mathrm{M} / 30$ & Affected & 20 & 9 & + & LAD; Q(V $\left.V_{L}\right)$, LVH, ST-T $\left(V_{3}, V_{6}\right)$ \\
\hline IV-22 & $\mathrm{F} / 25$ & Affected & 17 & 8 & - & RAD; ST-T $\left(D_{2}, D_{3}, V_{F}, V_{5}, V_{6}\right) ; L V H$ \\
\hline IV-1 & $F / 20$ & Unknown & 8 & 8 & - & $P$, ST-T $\left(D_{3}, V_{F}\right)$ \\
\hline IV-8 & $F / 28$ & Unaffected & 11 & 11 & - & $\mathrm{N}$ \\
\hline IV-9 & $F / 24$ & Unaffected & 10 & 9 & - & $\mathrm{N}$ \\
\hline IV-17 & $F / 24$ & Unaffected & 9 & 9 & - & Minor $S T$ - $T$ changes in $D_{2}, D_{3}, V_{F}$ \\
\hline IV-20 & $\mathrm{F} / 12$ & Unaffected & 8 & 8 & - & $\mathrm{N}$ \\
\hline IV-21 & $\mathrm{M} / 18$ & Unaffected & 10 & 10 & - & $\mathrm{N}$ \\
\hline
\end{tabular}

S, end diastolic interventricular septum thickness; LVFW, left ventricular end-diastolic free wall thickness; SAM, systolic anterior motion of the mitral valve; M, male, F, female, LVH, left ventricular hypertrophy; $Q$, abnormal Q wave; ST-T, ST-T modifications; P, abnormal P wave; $R A D$, right axis deviation; $L A D$, left axis deviation; $D_{2}, D_{3}, V_{3}, V_{5}, V_{6}, V_{F}, V_{L}$ are conventional electrocardiographic leads; $N$, normal. 
Table V. Comparison of the Ages, Clinical Status, and Echocardiographic and Electrocardiographic Data of the Individuals of Family 730 Carrying the Mutation

\begin{tabular}{|c|c|c|c|c|c|c|}
\hline & Sex/age & $\begin{array}{l}\text { Clinical } \\
\text { status }\end{array}$ & $\mathbf{S}$ & LVFW & SAM & ECG \\
\hline & $y r$ & & $\mathrm{~mm}$ & $\mathrm{~mm}$ & & \\
\hline II-2 & $F / 51$ & Affected & 10 & 9 & - & ST-T $\left(D_{2}, D_{3}, V_{F}\right)$ \\
\hline II-4 & $F / 52$ & Affected & 17 & 10 & - & LVH, ST-T $\left(\mathrm{V}_{2} \rightarrow \mathrm{V}_{6}, \mathrm{D}_{1}, \mathrm{D}_{2}, \mathrm{~V}_{\mathrm{L}}, \mathrm{V}_{\mathrm{F}}\right)$ \\
\hline II-6 & $\mathrm{F} / 55$ & Affected & 14 & 10 & - & LAH; LAD; ST-T $\left(D_{1} V_{L}\right), Q\left(D_{2}, D_{3}, V_{F}\right)$ \\
\hline II-8 & $\mathrm{M} / 48$ & Affected & 14 & 12 & - & LVH; ST-T $\left(V_{3} \rightarrow V_{6}\right)$ \\
\hline III-1 & $\mathbf{M} / 33$ & Affected & 13 & 9 & - & LAH, LVH, Q( $\left.\mathrm{D}_{3}, \mathrm{~V}_{\mathrm{F}}\right), \mathrm{ST}-\mathrm{T}\left(\mathrm{D}_{1}, \mathrm{D}_{2}, \mathrm{D}_{3}, \mathrm{~V}_{\mathrm{F}}, \mathrm{V}_{5}, \mathrm{~V}_{6}\right)$ \\
\hline III-3 & $\mathrm{F} / 31$ & Affected & 10 & 10 & - & $\mathrm{Q}\left(\mathrm{V}_{3} \rightarrow \mathrm{V}_{6}\right)$ \\
\hline III-4 & $\mathrm{M} / 19$ & Unknown & ND & ND & ND & $\mathrm{N}$ \\
\hline
\end{tabular}

LAH, left atrial hypertrophy, ND, non determined.

(9-13) and in one Korean family (14). $403^{\text {Arg } \rightarrow \text { Leu }}$ and $403^{\text {Arg } \rightarrow \text { Trp }}$ are clearly two separate mutational events, whose discovery indicates the existence of a mutation hot spot in the $\beta$-myosin heavy chain gene. Missense mutations have not been identified in active sites located in the head part of the $\beta$-MHC, nor in the rod part of the protein. This is probably because of either the lethality or to the absence of physiopathological consequences of such events. So far, mutations have only been identified around the active sites in the head part of the $\beta$ MHC. Thus, one might hypothesize that the substitution of the arginine residue 403 , a very conserved amino acid (9), plays a major role in the physiopathology of the $\mathrm{FHC}$, which remains to be elucidated.

Mutation $403^{\mathrm{Arg} \rightarrow \text { Leu }}$ appeared to be malignant in family 720: its phenotypic expression was characterized by a severe and asymmetrical pattern of left ventricular hypertrophy on echocardiogram, a high incidence of cardiac failures and sudden deaths or transitions to dilation of the left ventricle associated with marked wall and fiber hypertrophy. In a younger individual, the autopsy exhibited a typical form of asymmetrical FHC without any sign of cardiac dilation. These findings suggest that the cardiac dilation observed in patients who are obligate carriers of the disease was the evolution of a previously hypertrophic form of cardiomyopathy. Although mutation $403^{\mathrm{Arg} \rightarrow \mathrm{Leu}}$ was associated with a high incidence of cardiac events, six fourth-generation young adults carried the mutation without any phenotypic expression. The follow-up of these individuals by serial cardiovascular examinations will help to determine whether they will develop the disease in the future and to what extent. In family 730 , the phenotypic-genotypic relationship must be discussed with caution because of the small size of the pedigree. However, the degree of left ventricular hypertrophy appeared to be moderate in the affected subjects and there was no report of sudden death, suggesting that in this family the mutation involved is less severe than the $403^{\mathrm{Arg} \rightarrow \mathrm{Leu}}$ mutation. Finally, a partial penetrance was found with the $403^{\text {Arg } \rightarrow \text { Leu }}$ mutation in family 720 and, to some extent, with the $403^{\mathrm{Arg} \rightarrow \text { Trp }}$ in family 730 . This contrasts with the full penetrance observed in the large pedigrees carrying the previously described $403^{\text {Arg } \rightarrow \text { Gln }}$ mutation $(10,11)$. Varying clinical patterns of FHC thus appear to be associated with the presence of three different amino acids at position 403 in $\beta$-myosin heavy chain protein. Analysis of other pedigrees carrying these specific mutations will be necessary to confirm these observations.

\section{Acknowledgments}

We are indebted to the family members, without whose participation this work could not have been done. We are grateful to $D$. Hillaire for her contribution in the collect of the families, to Dr. C. Almange and Dr. M. Laurent for performing most of the echocardiographic examinations, and to Dr. R. Williamson for his interest in the study.

This work was supported by Institut National de la Sante et de la Recherche Médicale (Réseau de recherche clinique no. 492010), the Association Française contre les Myopathies and the Deutsche Forschungsgemeinschaft.

\section{References}

1. Maron, B. J., and V. J. Ferrans. 1978. Ultrastructural features of hypertrophied human ventricular myocardium. Prog. Cardiovasc. Dis. 21:207-238.

2. Maron, B. J., P. F. Nichols, L. W. Pickle, Y. E. Wesley, and J. J. Mulvihill. 1984. Patterns of inheritance in hypertrophic cardiomyopathy. Assessment by M-mode and two-dimensional echocardiography. Am. J. Cardiol. 53:1087-1094.

3. Jarcho, J. A., W. Mc Kenna, J. A. P. Pare, S. D. Solomon, R. F. Holcombe, S. Dickie, T. Levi, H. Donis-Keller, J. G. Seidman, and C. E. Seidman. 1989. Mapping a gene for familial hypertrophic cardiomyopathy to chromosome 14ql. N. Engl. J. Med. 321:1372-1378.

4. Solomon, S. D., J. A. Jarcho, W. McKenna, A. Geisterfer-Lowance, R. Germain, R. Salerni, J. G. Seidman, and C. E. Seidman. 1990. Familial hypertrophic cardiomyopathy is a genetically heterogeneous disease. J. Clin. Invest. 86:993-999.

5. Hejtmancik, J. F., P. A. Brink, J. Towbun, R. Hill, L. Brink, T. Tapscott, A. Trakhtenbroit, and R. Roberts. 1991. Localization of gene for familial hypertrophic cardiomyopathy to chromosome $14 \mathrm{q} 1$ in a diverse US population. Circulation. 83:1592-1597.

6. Epstein, N. D., L. Fananapazir, H. J. Lin, J. Mulvihill, R. White, J.-M. Lalouel, R. P. Lifton, A. W. Nienhuis, and M. Leppert. 1992. Evidence of genetic heterogeneity in five kindreds with familial hypertrophic cardiomyopathy. Circulation. 85:635-647.

7. Schwartz K., J. S. Beckmann, C. Dufour, F. Fougerousse, L. Faure, L. Carrier, C. Hengstenberg, F. Cambien, D. Cohen, M. Ferrière, et al. 1992. Exclusion of myosin heavy chain and cardiac actin gene involvement in hypertrophic cardiomyopathies of several french families. Circ. Res. 71:3-8.

8. Ko, Y. L., W. P. Lien, J. J. Chen, C. W. Wu, T. K. Tang, and C. C. Liew. 1992. No Evidence for linkage of familial hypertrophic cardiomyopathy and chromosome 14q1 locus D14S26 in a Chinese family: evidence for genetic heterogeneity. Hum. Genet. 89:597-601.

9. Geisterfer-Lowrance, A. A. T., S. Kass, G. Tanigawa, H.-P. Vosberg, W. McKenna, C. E. Seidman, and J. G. Seidman. 1990. A molecular basis for familial hypertrophic cardiomyopathy: a $\beta$ cardiac myosin heavy chain gene missense mutation. Cell. 62:999-1006.

10. Epstein, N. D., G. M. Cohn, F. Cyran, and L. Fananapazir. 1992. Differences in clinical expression of hypertrophic cardiomyopathy associated with two distinct mutations in the $\beta$-myosin heavy chain gene. A $908^{\text {Leu } \rightarrow \text { Val }}$ Mutation and a $403^{\text {Arg } \rightarrow \text { Gln }}$ Mutation. Circulation. 86:345-352.

11. Watkins, H., T. Rosenzweig, D.-S. Hwang, T. Levi, W. McKenna, C. E. Seidman, and J. G. Seidman. 1992. Characteristics and prognostic implications 
of myosin missense mutations in familial hypertrophic cardiomyopathy. $N$. Engl. J. Med. 326:1106-1114.

12. Perryman, M. B., Q.-T. Yu, A. J. Marian, A. Mares, G. Czernuszewicz, J. Ifegwu, R. Hill, and R. Roberts. 1992. Expression of a missense mutation in myocardial tissue in hypertrophic cardiomyopathy. J. Clin. Invest. 90:271-277.

13. Mares, A., A. J. Marian, Q.-T. Yu, G. Z. Czermuszewicz, G. Gooch, T. Tapscott, D. Kelly, J. Towbin, M. B. Perryman, and R. Roberts. 1992. Genetic screening of 75 families with hypertrophic cardiomyopathy show missense mutations the most common genetic defect. Circulation. 86(Suppl I):I-228.

14. Fananapazir, L., and N. Epstein. 1992. Genotype-phenotype studies in hypertrophic cardiomyopathy: insights provided by comparisons of kindreds with identical $\beta$ myosin heavy chain gene mutations. Circulation. 86(Suppl I):I228.

15. Rosenzweig, A., H. C. Watkins, D. S. Hwang, M. Miri, W. McKenna, T. A. Traill, J. G. Seidman, and C. E. Seidman. 1991. Preclinical diagnosis of familial hypertrophic cardiomyopathy by genetic analysis of blood lymphocytes. N. Engl. J. Med. 325:1753-1760.

16. Harada, H., A. Kimura, H. Nishi, Y. Koga, T. Sasazuki, and H. Toshima. 1992. Genetic analysis of hypertrophic cardiomyopathy. Circulation. 86(Suppl I):I-591.

17. Anan, R., L. Thierfelder, H. Watkins, and W. McKenna. 1992. Identification of novel myosin mutations that cause familial hypertrophic cardiomyopathy. Circulation. 86(Suppl I):I-229.

18. Nishi, H., A. Kimura, H. Harada, H. Toshima, and T. Sasazaki. 1992. Novel missense mutation in cardiac $\beta$ myosin heavy chain gene found in a japanese patient with hypertrophic cardiomyopathy. Biochem. Biophys. Res. Commun. 188:379-387.

19. Watkins, H., L. Thierfelder, D.-S. Hwang, W. McKenna, J. G. Seidman, and C. E. Seidman. 1992. Sporadic hypertrophic cardiomyopathy due to de novo myosin mutations. J. Clin. Invest. 90:1666-1671.

20. Fananapazir, L., M. Dalakas, F. Cyran, G. Cohn, and N. Epstein. 1992 Central core disease is present in hypertrophic cardiomyopathy with distinct mutations in the beta myosin heavy chain gene. Circulation. 86(Suppl I):I-229.

21. Al-Mahdawi, S., S. Chamberlain, J. Cleland, P Nihoyannopoulos, D. Gilligan, J. French, L. Choudhury, R. Williamson, and C. Oakley. 1993. Identifcation of a mutation in the $\beta$ cardiac myosin heavy chain gene in a family with hypertrophic cardiomyopathy. Br. Heart J. 69:136-141.
22. Watkins, H., C. MacRae, L. Thierfelder, Y. H. Chou, M. Frenneaux, W. McKenna, J. G. Seidman, and C. E. Seidman. 1993. A disease locus for familial hypertrophic cardiomyopathy maps to chromosome 1q3. Nature Genet. 3:333337.

23. Carrier, L., and Hengstenberg, C., J. Beckmann, P. Guicheney, C. Dufour, J. Bercovici, E. Dausse, I. Berebbi-Bertrand, C. Wisnewski, D. Pulvenis, et al. 1993. Mapping of a novel gene for familial hypertrophic cardiomyopathy to chromosome 11. Nature Genet. 4:311-313.

24. Richards, E. J. 1987. Preparation and analysis of DNA. In Current Protocols in Molecular Biology. F. M. Ausbel, R. Brent, and R. E. Kingston, editors. John Wiley \& Sons, Inc., New York. pp. 2.0.3-2.2.2.

25. Henry, W. L., and J. M. Gradin, J. H. Ware. 1980. Echocardiographic measurements in normal subjects from infancy to old age. Circulation. 62:10541060.

26. Weissenbach, J., G. Gyapay, C. Dib C., A. Vignal, J. Morissette, P. Millasseau, G. Vaysseix, and M. Lathrop. 1992. A second-generation linkage map of the human genome. Nature (Lond.) 359:794-801.

27. Keen, J., C. Lester, C. Inglehearn, A. Curtis, and S. Bhattacharya. 1991. Rapid detection of single-base mismatches as heteroduplexes on Hydrolink gels. Trends Genet. 7:5.

28. Liew, C. C., M. J. Sole, K. Yamauchi-Takihara, B. Kellam, D. H. Anderson, L. Lin, and J. C. Liew. 1990. Complete sequence and organization of the human cardiac $\beta$-myosin heavy chain gene. Nucleic Acids Res. 18:3647-3651.

29. Gyllensten, U. B., and H. A. Erlich. 1988. Generation of single-stranded DNA by the polymerase chain reaction and its application to direct sequencing of the HLA-DQA locus. Proc. Natl. Acad. Sci. USA. 85:7652-7656.

30. Lathrop, G. M., and J. M. Lalouel. 1984. Easy calculations of LOD scores and genetics risks on small computers. Am. J. Hum. Genet. 36:460-465.

31. Cooper, D. N., and H. Youssoufian. 1988. The CpG dinucleotide and human genetic disease. Hum. Genet. 78:151-155.

32. Abadie, V., S. Lyonnet, N. Maurin, M. Berthelon, C. Caillaud, F. Giraud, J. F. Mattei, J. Rey, F. Rey, A. Munnich. 1989. CpG dinucleotides are hot spots in phenylketonuria. Genomics. 5:936-939.

33. Bottema, C. D., M. J. Bottema, R. P. Ketterling, H. S. Yoon, R. L. Janco, J. A. Phillips, and S. Sommer. 1991. Why does the human factor IX gene have a G + C content of 40\%? Am. J. Hum. Genet. 49:839-850. 